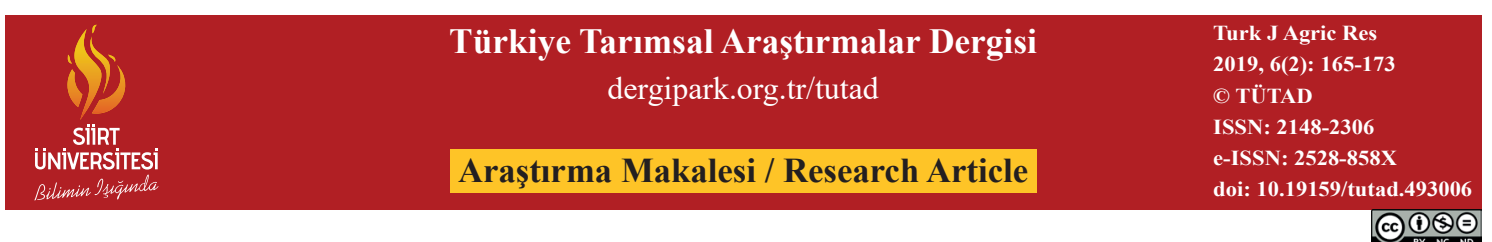

\title{
Fıstık (Pistacia vera L.) Yaprağından Gümüş Nanopartikül (AgNP)’lerin Sentezi, Karakterizasyonu ve Antimikrobiyal Aktivitesinin İncelenmesi
}

\author{
Abdullah EREN ${ }^{1 *}$, Mehmet Firat BARAN ${ }^{2}$ \\ ${ }^{1}$ Artuklu Üniversitesi, Kızıltepe Meslek Yüksekokulu, Organik Tarım Bölümü, Mardin, TÜRKİYE \\ ${ }^{2}$ Artuklu Üniversitesi, Sağlık Hizmetleri Meslek Yüksekokulu, Tıbbi Hizmetler Bölümü, Mardin, TÜRKIYYE
}

\begin{tabular}{ll}
\hline \multicolumn{1}{c}{ Geliş Tarihi/Received: 06.12.2018 } & Kabul Tarihi/Accepted: 30.05 .2019 \\
\hline ORCID IID (Yazar surasina göre / by author order) \\
\hline Dorcid.org/0000-0003-1187-7978 Dorcid.org/0000-0001-8133-6670 \\
\hline
\end{tabular}

Sorumlu Yazar/Corresponding Author: abdullaheren@artuklu.edu.tr

Öz: Bu çalışmanın amacı, fıstık (Pistacia vera L.) bitki ekstraktı kullanılarak, yeşil sentez yöntemi ile gümüş nanopartikül (AgNP)'lerini sentezlemektir. Yeşil sentez; çevre dostu ve maliyet açısından ucuz olması, kimyasal ve fiziksel yöntemlerden daha çok tercih edilen nanopartiküllerin kolay bir şekilde elde edilmesi ile bilinen biyolojik bir yöntemdir. Reaksiyon sonucunda elde edilen AgNP'ler, UV görünür spektrofotometre (UV-vis), fourier-dönüştürülmüş kızılötesi spektroskopisi (FTIR), X-Ișını kırınımı (XRD), termogravimetrik ve diferansiyel termal analizi (TGA-DTA), taramalı elektron mikroskobu ve enerji yayılımlı X-ışını cihazı (SEM-EDX) kullanılarak karakterize edilmiştir. Gümüş nanopartiküllerin $460.67 \mathrm{~nm}$ 'de maksimum absorbansa sahip olduğu görülmüştür. AgNP'lerin indirgenmesinde rol olan fitokimyasalları analiz etmek için FTIR analizi yapılmıştır. Debye-Scherrer's denkleminden yararlanarak sentezlenen nanoparçacıkların kristal boyutunun 16.7 nm olduğu hesaplanmıştır. AgNP'lerin küresel görünümde olduğu transmisyon elektron mikroskobu ile tespit edilmiştir. Sentezlenen AgNP'lerin antimikrobiyal etkisi gram pozitif ve gram negatif bakterileri ve fungus (maya) üzerinde minimum inhibitör konsantrasyonu (MIC) metodu ile test edilmiştir. Sonuç olarak, sentezlenen gümüş nanopartiküllerin antimikrobiyal etki gösterdiği belirlenmiştir.

Anahtar Kelimeler: Antimikrobiyal aktivite, AgNP, yeşil sentez, Pistacia vera L.

\section{Synthesis, Characterization and Investigation of Antimicrobial Activity of Silver Nanoparticles (AgNP) from Pistachio (Pistacia vera L.) Leaf}

\begin{abstract}
The aim of this study is to synthesize silver nanoparticles (AgNPs) by green synthesis methods using pistachio (Pistacia vera L.) plant extract. Green synthesis is a biological method in which nanoparticles are easily obtained; as well as being environmentally friendly and inexpensive in terms of cost, and being more preferred than chemical and physical methods. AgNPs obtained by the reaction were chacarterized with UV visible spectrophotometer (UV-vis), fouriertransformed infrared spectroscopy (FTIR), X-ray diffraction (XRD), thermogravimetric and differential thermal analysis (TGA-DTA), scanning electron microscopy and energy dispersive X-ray device (SEM-EDX). Silver nanoparticles were found to have a maximum absorbance at $460.67 \mathrm{~nm}$. FTIR analysis was performed to analyze the phytochemicals involved in the reduction of AgNPs. Using the Debye-Scherrer's equation, the crystal size of the synthesized nanoparticles was calculated as $16.7 \mathrm{~nm}$. AgNPs spherical appearance were detected by transmission electron microscopy. The antimicrobial effect of synthesized AgNPs were tested on gram-positive and gram-negative bacteria, and by the minimum inhibitory concentration (MIC) method on fungi (yeast). As a result, it was determined that the synthesized silver nanoparticles had antimicrobial effect.
\end{abstract}

Keywords: Antimicrobial activity, AgNP, green synthesis, Pistacia vera $\mathrm{L}$. 


\section{Giriş}

Nanopartiküller 1-100 nm arasında değişen boyutlara sahip malzemelerdir (Ahmed ve ark., 2016). Nano parçacıklar; bio-medikal, kataliz, gıda, giyim, kozmetik endüstrisinde ve elektronik gibi bir çok alanda kullanılmaktadır (Gopinath ve ark., 2016; Saravanakumar ve ark., 2018; Selvakumar ve ark., 2018). Gümüş (Ag), bakterilere ve diğer mikroorganizmalara karş1 gösterdiği aktivite nedeniyle uzun yıllardır bir çok alanda antibakteriyel uygulamalarda kullanılmakta (Yang ve ark., 2012); gümüş nanopartikül (AgNP)'lerin, güçlü bir antibakteriyel aktiviteye sahip olduğu bazı araştırmacılar tarafından bildirilmektedir (Xu ve ark., 2011; Kung ve ark., 2018);

Öte yandan, tarım alanlarında çok fazla kullanılan ve küresel bir tehlike oluşturmaya başlayan herbisit ve pestisitlere alternatif çözümler araştırılmaktadır. Bu ilaçlar yerine antimikrobiyal ajanlar olarak AgNP'lerin kullanımının daha ekonomik ve etkili olduğu yapılan araştırmalarda görülmektedir (Kim ve ark., 2012; Stevanović ve ark., 2012).

Gümüş nanopartiküllerin elde edilmesi için çeşitli yöntemler kullanılmaktadır. $\mathrm{Bu}$ yöntemler içerisinde biyolojik yöntem, diğer (fiziksel ve kimyasal) yöntemlere göre çevre dostu ve ekonomik olmasından dolayı daha çok tercih edilmektedir (Chen ve ark., 2003; Francis ve ark., 2017). Gümüş nanopartiküllerin sentezinde, bitkisel kaynakların kullanımı, daha ekonomik ve uygulama prosesleri daha kolay olduğundan son zamanlarda daha fazla ilgi görmektedir (Song ve Kim, 2009; Pallela ve ark., 2018). Yeşil sentez ile elde edilen AgNP'lerin biouyumlu olması özelliği ile de canlı uygulamalar için önemli bir nitelik taşımaktadır (Rajan ve ark., 2015; Dadashpour ve ark., 2018).

Bu araștırmada, fistık (Pistacia vera L.) bitkisi yapraklarından elde edilen bitki ekstraktı (özütü) ile sentezlenen AgNP'lerin karakterize edildikten sonra anti-mikrobiyal etkileri incelenmiştir.

\section{Materyal ve Yöntem}

Araştırmada, Türkiye'nin Güneydoğu Anadolu Bölgesi Mardin ili sınırlarında toplanan yeşil fistık (Pistacia vera L.) yaprakları çalışmanın ana materyalini (AgNP'lerin sentezi için özüt ham maddesini) oluşturmaktadır. Çalışmada kullanılan diğer materyaller, sentez aşamasında kullanılan MERC marka katı gümüş nitrat $\left(\mathrm{AgNO}_{3}\right.$, saflık $\%$ 99.8) ile antimikrobiyal uygulamalarda kullanılmak üzere ticari olarak temin edilen antibiyotikler (vankomisin, frukozanol ve colistin) oluşturmaktadır.

\subsection{Bitki özütünün hazırlanması}

Toplanan yeşil fistık yaprakları önce çeşme suyu ile daha sonra saf suyla yıkanmış; oda koşullarında kurutulduktan sonra, ögütülmüştür. Öğ̈üülen örneklerden $25 \mathrm{~g}$ alınıp $250 \mathrm{~mL}$ saf su ile 70-80 ${ }^{\circ} \mathrm{C}$ 'de kaynamaya tabi tutulmuş, özüt oluşumu (renk) gözlemlendikten sonra oda sıcaklığına $\left(25^{\circ} \mathrm{C}\right)$ kadar soğumaya bırakılmıştır. Daha sonra, Whatmann No: 1 filtre kâğ 1 d1 kullanılarak filtrasyon yapılmış ve elde edilen ekstrakt $4{ }^{\circ} \mathrm{C}$ 'de muhafaza edilmiştir.

\subsection{AgNP'lerin sentezi}

AgNP'lerin oluşum ve varlığının incelenmesi zamana bağlı olarak UV-vis spektrofotometre ile yapılan ölçümlerle ortaya konmaktadır. AgNP'lerin sentezi için önceden hazırlanan $1 \mathrm{mM}$ $500 \mathrm{ml} \mathrm{AgNO}_{3}$ sulu çözeltisi ile $125 \mathrm{ml}$ fistık bitkisi yaprak özütü 1000 ml'lik bir erlen içerisinde oda sıcaklığında sabit koşullarda reaksiyona bırakılmıştır. Gümüş iyonlarının indirgenmesi ile şeffaf renkli çözeltinin koyu kahverengiye doğru renk değişimi 30 dakika içinde gözlenmiştir. Koyu kahverengiye doğru olan renk değişimi AgNP'lerin oluşumu esnasında plazma yüzeyindeki titreşimler meydana getirmesi ile gözlenmektedir (Gupta ve ark., 2017). Sentezlenen AgNP'ler UV-vis spektroskopisinde 30 dakika sonunda $460.67 \mathrm{~nm}$ dalga boyunda maksimum absorbans değeri olarak belirlenmiştir.

Oluşan koyu renkli solüsyon 10.000 rpm'de 5 dakika santrifüj edilerek üst sıvı faz uzaklaştırılmış ve kalan katı kısım birkaç kez saf su ile yıkama işlemine tabi tutulmuştur. Elde edilen katı kısım (AgNP) etüvde $65{ }^{\circ} \mathrm{C}$ 'de 48 saat kurumaya bırakılmıştır. Karakterizasyon işlemlerinde kullanılmak üzere saklanmıştır.

\subsection{AgNP'lerin karakterizasyon teknikleri}

Sentezlenmiş AgNP'lerin UV-vis spektrumları, UV-1601 220V Shimadzu spektrofotometresinde 300-800 nm dalga boyu aralığında belirlenmiştir. Gümüş nanoparçacıklarının kristal yapıları RadBDMAX II bilgisayar kontrollü X-ışını diftraktometresi ile $3^{\circ} \leq 2 \theta \geq 80^{\circ}$ aralığında analiz edilmiştir. Gümüş nanopartiküllerin kristal boyutu, Debye-Scherrer's eşitliği (Eşitlik 1)'nden yararlanılarak hesaplanmıştır (Ambika ve Sundrarajan, 2015).

$$
D=K \lambda /(\beta \cos \theta)
$$

Eşitlikte D, parçacığın kristal çap1 $(\mathrm{nm}) ; \mathrm{K}$, sabit sayıy (0.90); $\lambda$, dalga boyu X-ray'1 $\left(1.5406 \mathrm{~A}^{\circ}\right) ; \beta$, 
maksimum pikin yarı yükseklikteki genişliği (rad.); $\theta$, Bragg açısı (derece)'nı ifade etmektedir.

Gümüş nanopartiküllerin boyut ve morfolojisi taramalı elektron mikroskobu (SEM) EVO 40 LEQ kullanılarak tespit edilmiştir. SEM-enerji dağılımlı X-ışını (SEM-EDX) spektroskopisi element kompozisyonunda AgNP'lerin saf gümüş veya gümüş oksit parçacıklarının oluşumunu doğrulamak için kullanılmıştır. Perkin Elmer Spektrum One markalı FTIR Cihazı ile 4000-400 $\mathrm{cm}^{-1}$ aralığında yapılan analizle bitki özütünün yapısındaki mevcut fonksiyonel grupların varlığını ve reaksiyon sonunda indirgemede rol alan fonksiyonel grupların değişimi incelenmiştir. Shimadzu TGA-50 cihazı ile termal gravimetrik analizler (DTA-TGA) sabit 1sitma hizında $\mathrm{N}_{2}$ atmosferi altında $25{ }^{\circ} \mathrm{C} \quad \operatorname{dak}^{-1} \quad\left(30-900 \quad{ }^{\circ} \mathrm{C}\right)$ sentezlenen gümüş nanoparçacıkların bozunma sıcaklıkları belirlenmiştir.

\subsection{AgNP'lerin antimikrobiyal aktivitesi}

Gümüş nanopartiküllerin antimikrobiyal aktiviteleri, minimum inhibisyon konsantrasyonu (MIC) metodu ile belirlenmiştir (Wang ve ark., 2017). Bu amaçla sentezlenen AgNP'lerin antimikrobiyal aktiviteleri için gram pozitif (Staphylococcus aureus ATCC 29213) ve gram negatif (Escherichia coli ATCC 25922) bakteriler ile mantar (Candida albicans) suşları bir gece inkübasyona bırakılmıştır. Mikrodilüsyon yöntemi için 96'lı mikro plaka kuyucukları kullanılmıştır. Mikrodilüsyon yöntemi ile yürütülen uygulamalarda 96'lı mikro plaka kuyucuklarına bakteriler için muller hinton fungus için ise RPMI (hücre kültüründe kullanılan büyüme ortamı) besiyeri eklenmiştir. Gümüş nanopartikülleri ayarlanmış konsantrasyonlarından bir seri dilüsyon hazırlanmasının ardından AgNP çözeltileri mikro plakalara eklenmiş ve dilusyon yapılmıştır. Daha sonra 0.5 McFarland'a göre hazırlanan ve ayarlanan mikroorganizma çözeltilerinden belirli miktarda mikroplakalara ilave edilerek $37{ }^{\circ} \mathrm{C}$ de bir gece inkübasyona bırakılmıştır. İnkübasyon sonrasında üremenin olmadiğı en düşük konsantrasyon MIC değeri olarak belirlenmiştir (Elshikh ve ark., 2016).

\section{Bulgular ve Tartışma}

\subsection{X-ray kırınımlı XRD analizi}

Gümüş nanopartiküllerin küresel yapılarının çapları (111), (200), (220) ve (311) tabakalarındaki yansımalar1 siras 1 ile $38.10^{\circ}, 44.05^{\circ}, 64.52^{\circ}$ ve $77.46^{\circ}$ değerlerinin kübik kristal yapıda olduğu tespit edilmiştir (Şekil 1). Debye-Scherrer's denklemi (Eşitlik 1) ile $16.7 \mathrm{~nm}$ kristal çapa sahip olduğu hesaplanmıştır.

Calotropis procera çiçek ekstraktı kullanılarak yapılan sentez çalışmasında (111), (200), (220) ve (311) tabakalarında bulunan yansımalar ve sirası ile $38^{\circ}, 44^{\circ}, 64^{\circ}$ ve $77^{\circ}$ 'deki değerleri AgNP'lerin kübik kristal yapısına ait olduğu belirtilmiştir (Babu ve Prabu, 2011). Tinospora cordifolia bitki ekstraktı ile yapılan benzer bir çalışmada ise AgNP'lerin sentezinde (111), (200), (220), (311) yansımalarının ise $38.1^{\circ}, 44.3^{\circ}, 64.4^{\circ}$ ve $74.3^{\circ}$ değerleri AgNP'lerin kristal yapıya sahip olduğu bildirilmiştir (Selvam ve ark., 2017).

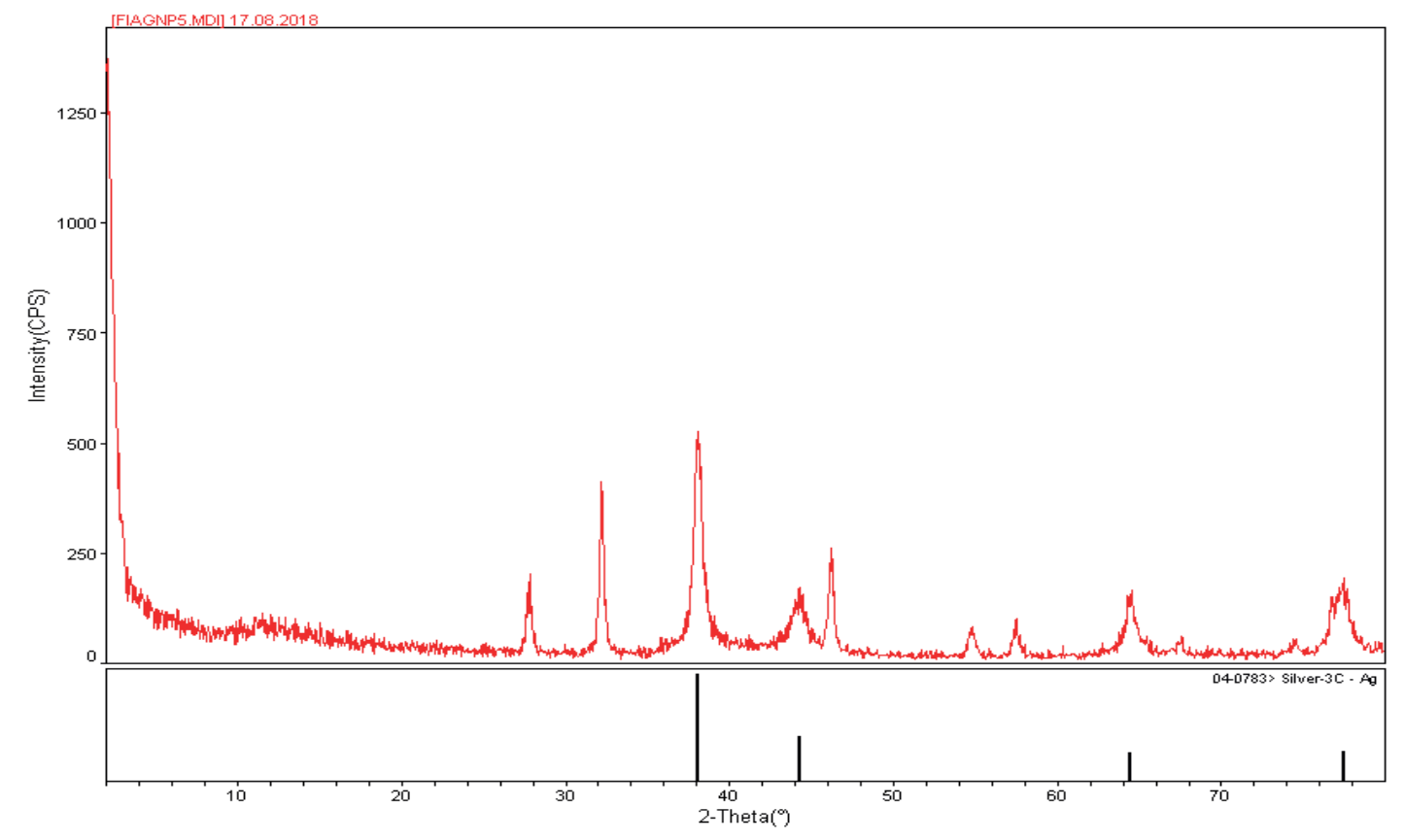

Şekil 1. Sentezlenmiş AgNP'lerin XRD sonuçları 


\subsection{UV-vis spektroskopi analizi}

UV-vis spektroskopisi analizinde farklı zamanlarda 5, 10, 15, 20, 25 ve 30 dakikalarda alınan örneklerde gümüş nanoparçacıklarının oluşumu gözlemlenmiştir. Şekil 2'de görüldüğü üzere oda sıcaklığında 1 saat karıştırmadan belli zaman aralıkları ile alınan numunelerin absorbsiyon spektrum değerleri ölçülerek maksimum 460.67 nm'de belirgin plazmon rezonans1 belirlenmiştir. Alsammarraie ve ark. (2018), zerdeçal (Curcuma longa) bitki özütü kullanılarak UV-vis analiz sonucunda $435 \mathrm{~nm}$ maksimum değer bulduklarını belirtmişlerdir. Bir diğer çalışmada mısır yapraklarının bitki özütü ile AgNP'lerin sentezinde $461 \mathrm{~nm}$ maksimum absorbans olarak belirlenmiştir (Eren ve Baran, 2019).

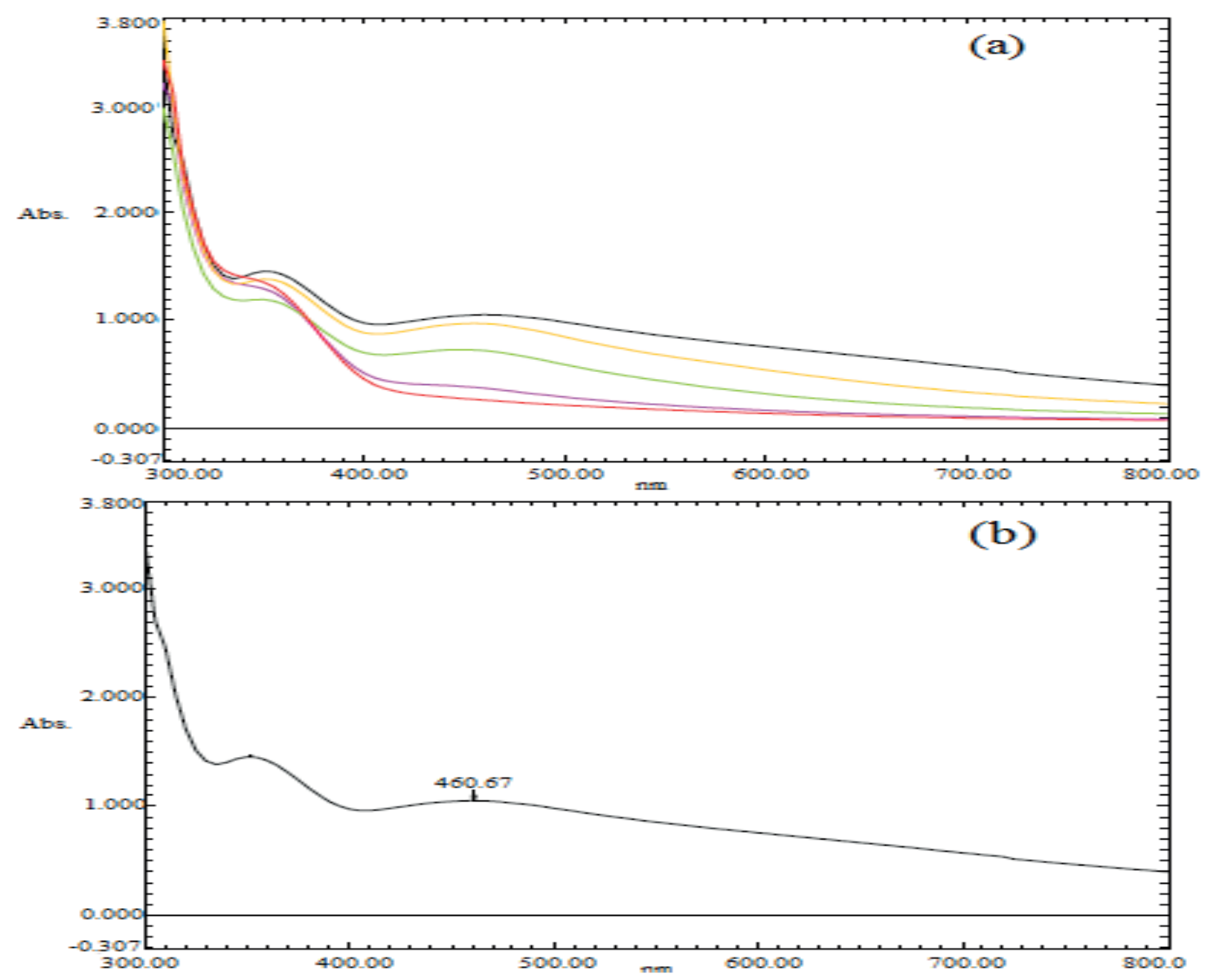

Şekil 2. a) UV görünür spektrokopisinde AgNP'lerin zamana bağlı olarak oluşumu, b) UV spektrofotometresinde sentezlen AgNP'in maksimum absorbans değeri

\subsection{FTIR spektroskopi analizi}

FTIR spektrumunun, fistık yaprak özütü ve sentezlenen AgNP'ler karşılaştırılarak reaksiyonun hangi fonksiyonel gruplar üzerinde gerçekleştiği hakkında bilgi vermektedir (Şekil 3). Fistık yaprak özütü yüzeyinde bulunan $-\mathrm{OH}$ fonksiyonel grubuna ait 3336.64-3334.57 $\mathrm{cm}^{-1}$ deki kuvvetli asimetrik esneme bandı, özüt ile Ag metali arasındaki etkileşim sonucu kayma göstermiştir. 3326.99 civarındaki piklerde yaklaşı $2 \mathrm{~cm}^{-1}$ arası bir frekans kayması meydana gelmiştir. Amid I bandına ait C-C ve C-N fonksiyonel gruplarına ait $1636.82-1636.48 \mathrm{~cm}^{-1}$ bandinda fazla bir kaymanın olmadığı ve bağlanmanın bu iki fonksiyonel grup üzerinde gerçekleştiği düşünülmektedir. Lakshman Kumar ve ark. (2016), tarafindan Echinochloa colona bitkisi ile AgNP'lerin yeşil sentezi ve arakterizasyonunda sentezledikleri AgNP'lerin verileri araştırmamızı desteklemektedir.

\subsection{AgNP'lerin TGA-DTA analizi}

Yeşil sentezle hazırlanan nanopartiküllerin 30$900{ }^{\circ} \mathrm{C}$ arasinda TGA ve DTA verileri $10{ }^{\circ} \mathrm{C}$ dak $^{-1}$ 1sıtma hızıyla $\mathrm{N}_{2}$ (g) atmosferinde $20 \mathrm{~mL} \mathrm{dak}^{-1}$ akış hızıyla analizi yapılmıştır. TGA eğrisi, termal bozunmalarından dolayı numune kütle kayb1 gösterir ve DTA eğrisi ise bozunmanın her aşamasında maksimum ayrışma sıcaklığını belirtmektedir (Baran, 2017).

Elde edilen AgNP'lerin 30-200 ${ }^{\circ} \mathrm{C}$ 'de kütle kaybının nemden kaynaklandığ $1,201-900{ }^{\circ} \mathrm{C}$ de selülozik materyallerden kaynaklanan kütle kaybı olduğu ve ayrıca çalışmada sentezlenen 


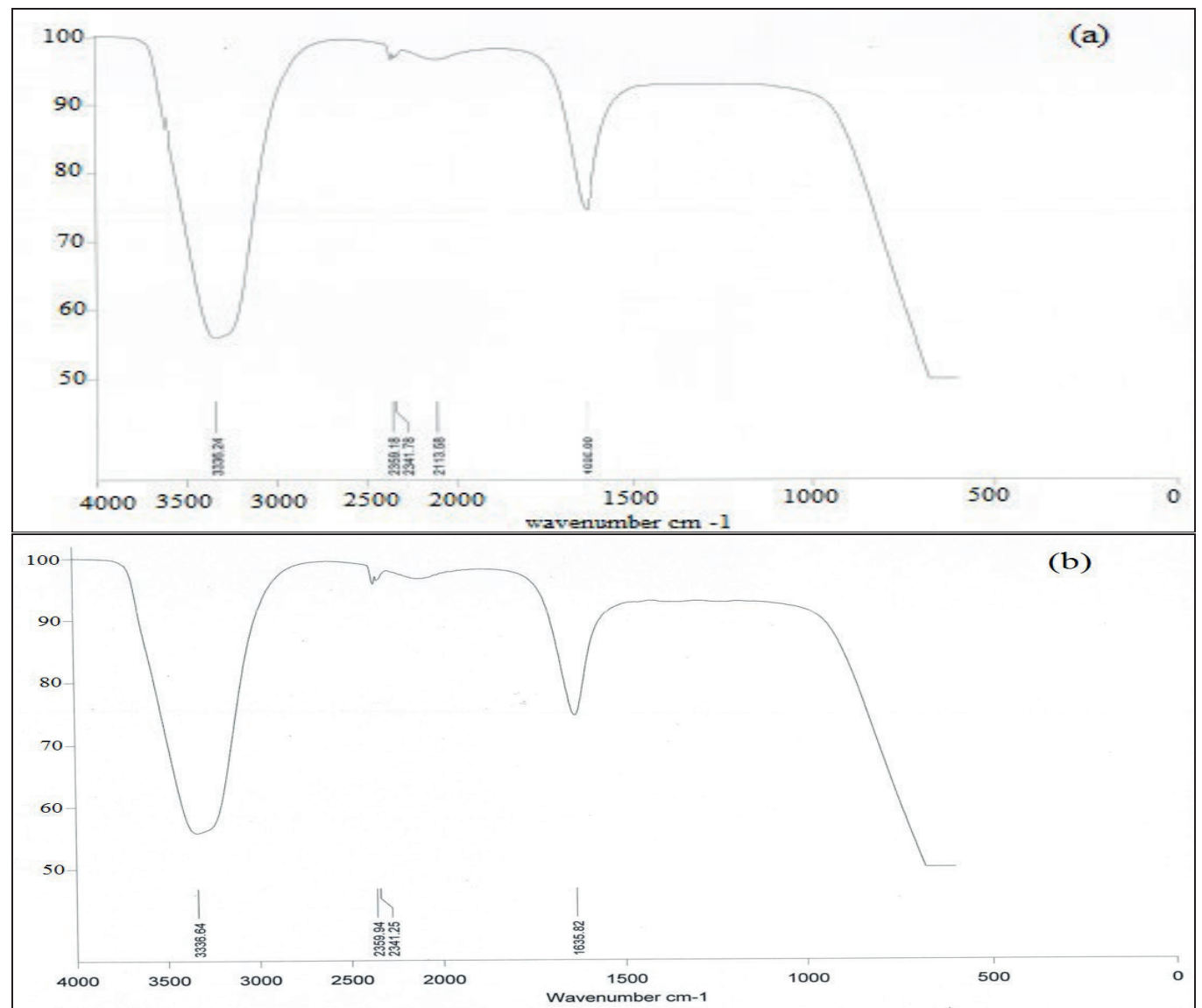

Şekil 3. a) Bitki özütünün FTIR spektrumu, b) Sentezlenen AgNP'lerin FTIR spektrumu

AgNP'lerin $900{ }^{\circ} C^{\prime}$ de \% 45'nin bozunduğu Şekil 4'te görülmektedir. Benzer bir çalıșmada AgNP'lerin TGA grafiği, $925{ }^{\circ} C^{\prime}$ 'ye kadar ki sıcaklık aralığında maddenin \% 55 'nin bozunduğu Kumar ve ark. (2017) tarafından belirtilmiştir.

\subsection{AgNP'lerin SEM ve EDX analizi}

F1stık yaprak özütünden elde edilen AgNP'lerin morfolojik özellikleri elektron mikroskobu (SEM) kullanılarak incelenmiştir. Gümüş nanopartiküllerin küresel yapıda olduğu belirlenmiştir (Şekil 5). Singh ve ark. (2015), bitki ekstraktları ile UV, XRD, SEM ve EDX analizleriyle AgNP'lerin karakterizasyonu ve biyosentezinde, EDX spektrumu kullanarak gümüş metal nano parçacıkların varlığını; küresel, altıgen, düzensiz şekillerde ve 10 ile $90 \mathrm{~nm}$ boyutlar arasında değiştiğini belirtmiştirler. Dehvari ve Ghahghaei (2018), Pulicaria undulata özütü kullanılarak sentez çalışmasında AgNP'lerin küresel görünümde olduklarını; Pallela ve ark. (2018) tarafından yapılan araştırmada da, Sida cordifolia bitki özütünden elde edilen ve SEMEDX sonuçlarına göre, AgNP'lerin küresel görünümde olduğunu, EDX sonuçlarında da büyük oranda element içeriğinin gümüşe ait olduğunu bildirmişlerdir.
Elde edilen AgNP'lerin enerji dağılımlı spektrumları SEM-EDX analiz sonuçları gümüş parçacıklarının 100 nm'den küçük olduğu ve EDX analizinde de element kompozisyonunun büyük oranda gümüşe ait olduğu görülmektedir (Şekil 6).

\subsection{Sentezlenen AgNP'lerin antimikrobiyal uygulamaları}

Gümüş nanopartiküller, $1 \mathrm{mM}$ gümüş nitrat ve ticari antibiyotiklerin MIC (mikroorganizmanın üremesinin engellendiği en düşük konsantrasyon) değerlerine bakılmış ve karşılaştırılmıştır. AgNP'lerin S. aureus ATCC 29213, E. coli ATCC 25922 bakterileri ve $C$. albicans maya üzerinde sirasiyla $0.041, \quad 0.662$ ve $0.165 \mu \mathrm{g} \mathrm{mL}^{-1}$ konsantrasyonlarda etkili olduğu değerlendirilmiştir (Şekil 7). Elde edilen sonuçlar AgNP'lerin $1 \mathrm{mM}$ gümüş nitrattan hazırlanan solüsyon ile ticari antibiyotikler karşısında daha düşük konsantrasyonlarda belirgin bir antibakteriyel aktivite ortaya koyduğu belirlenmiştir. Bitki kaynaklı sentezlenen AgNP'lerin S. aureus ATCC 29213 ve E. coli ATCC 25922'ye karşı güçlü bir antibakteriyel aktivite sergilendiği Khan ve ark. (2018), ayrıca Bryaskova ve ark. (2011) polivinil pirolidon (PVP) ile stabilize edilmiş AgNP'lerin 
antimikrobiyal aktivitesi test edilen bakteriyel ve fungal suşlara karşı güçlü bir antimikrobiyal etki gösterdiğini bildirmişlerdir. Carica papaya yaprak özütü ile elde edilen AgNP'lerin $25 \mu \mathrm{g} \mathrm{mL}^{-1}$ konsantrasyonun gram pozitif ve gram negatif bakteriler için minimum inhibisyon konsantrasyonuna sahip olduğunu bildirilmiştir (Banala ve ark., 2015).
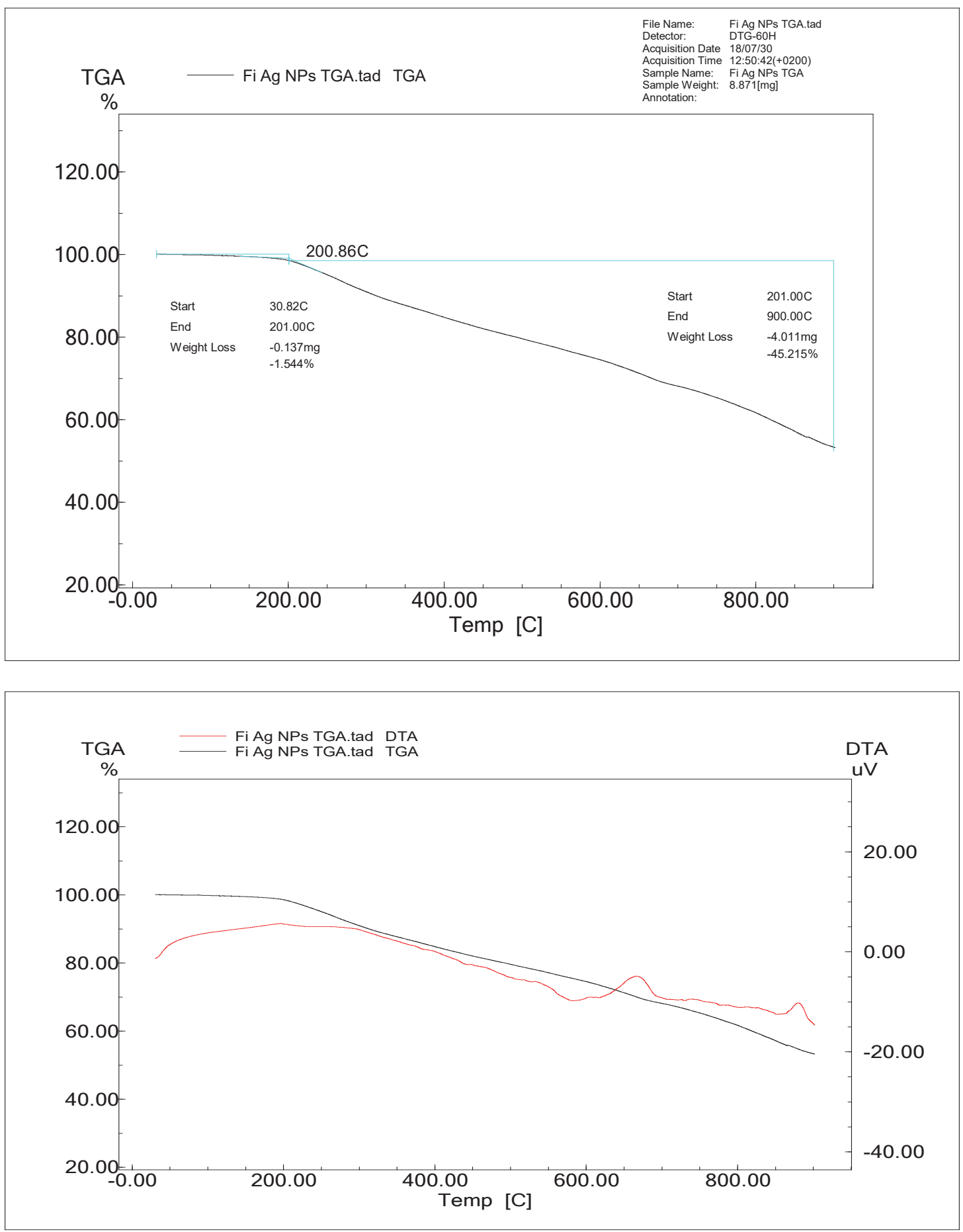

Şekil 4. Sentezlenen AgNP'lerin TGA ve DTA analiz sonucu 


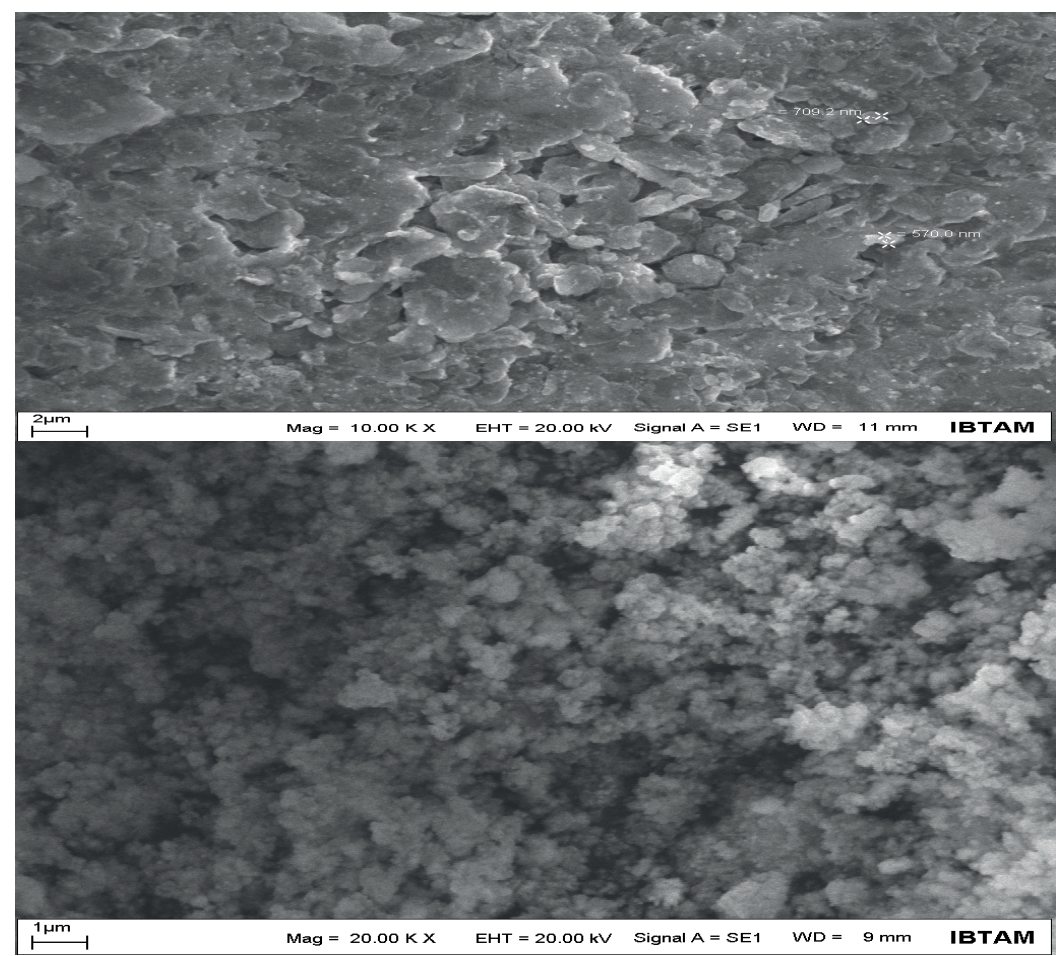

Şekil 5. Sentezlenen gümüş nanopartiküllerin SEM analizlerinin görüntüleri
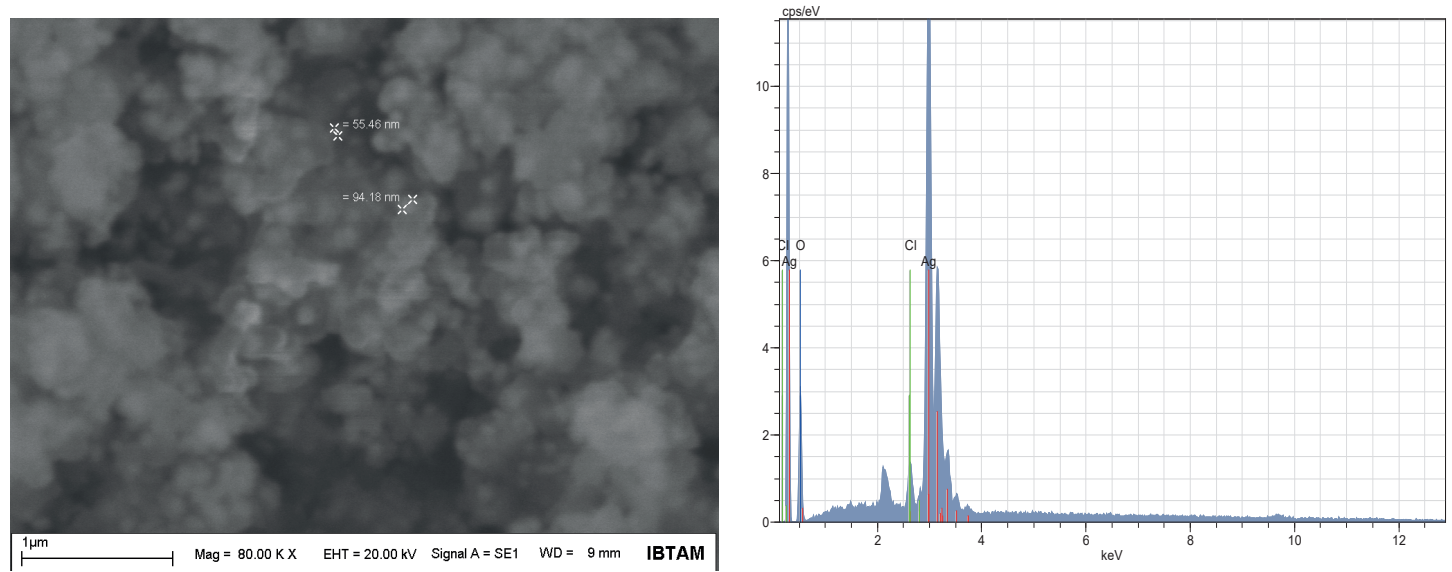

Şekil 6. AgNP'lerin EDX spektrumu

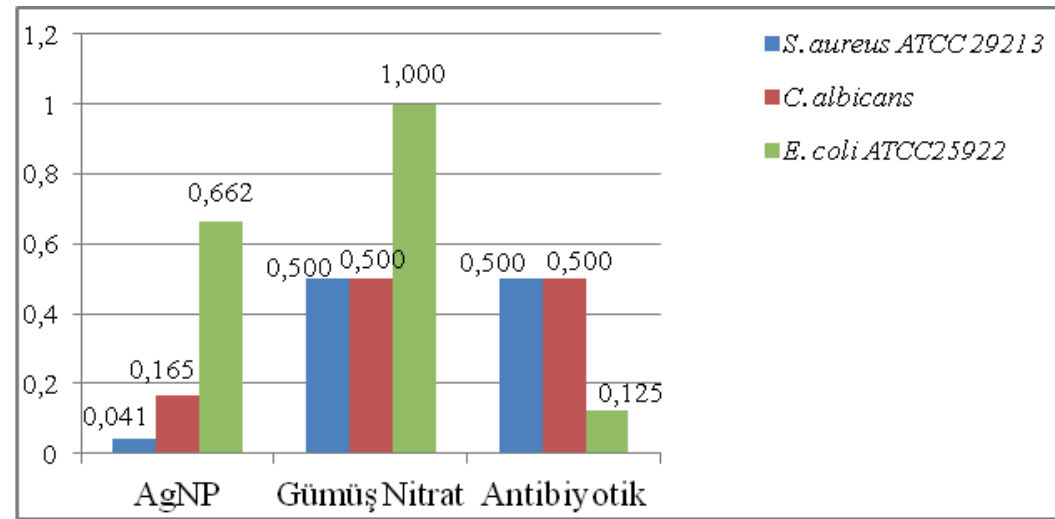

Şekil 7. AgNP'lerin minimum inhibitör konsantrasyon (MIC) değerleri $\left(\mu \mathrm{g} \mathrm{mL}^{-1}\right)$ 


\section{Sonuç ve Öneriler}

Nanopartiküllerin elde edilmesinde kullanılan yeşil sentez yöntemine olan ilgi her geçen gün artmaktadır. Yapılan çalışmada, fistık bitki yapraklarından elde edilen özüt ile AgNP'leri sentezlenerek karakterize edildikten sonra 460.67 nm maksimum absorbansa sahip küresel görünümde ve $16.7 \mathrm{~nm}$ kristal boyuta sahip oldukları belirlendi. $\mathrm{Bu}$ parçacıkların ticari antibiyotikler karşısında daha düşük konsantrasyonlarda etkili olduğu, yeșil yöntemle sentezlenen AgNP'lerin iyi bir antibakteriyel etkiye sahip olduğu tespit edilmiştir. Nanoteknolojik araştırmaların artmasıyla beraber, sentezlenmiş AgNP'ler, farmasötik ürünlerin üretilmesinde, ilaç sanayinde, biyomedikal ve endüstriyel ürünlerin daha faydalı hale gelebilmesi adına yeni bir alan açacaktır.

\section{Kaynaklar}

Ahmed, S., Ahmad, M., Swami, B.L., Ikram, S., 2016. A review on plants extract mediated synthesis of silver nanoparticles for antimicrobial applications: a green expertise. Journal of Advanced Research, 7(1): 1728.

Alsammarraie, F.K., Wang, W., Zhou, P., Mustapha, A., Lin, M., 2018. Green synthesis of silver nanoparticles using turmeric extracts and investigation of their antibacterial activities. Colloids and Surfaces B: Biointerfaces, 171: 398405.

Ambika, S., Sundrarajan, M., 2015. Antibacterial behaviour of Vitex negundo extract assisted $\mathrm{ZnO}$ nanoparticles against pathogenic bacteria. Journal of Photochemistry and Photobiology B: Biology, 146: 52-57.

Babu, S.A., Prabu, H.G., 2011. Synthesis of AgNPs using the extract of Calotropis procera flower at room temperature. Materials Letters, 65(11): 16751677.

Banala, R.R., Nagati, V.B., Karnati, P.R., 2015. Green synthesis and characterization of Carica papaya leaf extract coated silver nanoparticles through X-ray diffraction, electron microscopy and evaluation of bactericidal properties. Saudi Journal of Biological Sciences, 22(5): 637-644.

Baran, M.F., 2017. Sularda bazı ağır metallerin biyosorbsiyonu, Doktora Tezi, Dicle Üniversitesi, Fen Bilimleri Enstitüsü, Diyarbakır.

Bryaskova, R., Pencheva, D., Nikolov, S., Kantardjiev, T., 2011. Synthesis and comparative study on the antimicrobial activity of hybrid materials based on silver nanoparticles (AgNps) stabilized by polyvinylpyrrolidone (PVP). Journal of Chemical Biology, 4(4): 185-191.

Chen, J.C., Lin, Z.H., Ma, X.X., 2003. Evidence of the production of silver nanoparticles via pretreatment of Phoma sp. 3.2883 with silver nitrate. Letters in Applied Microbiology, 37(2): 105-108.
Dadashpour, M., Firouzi-Amandi, A., PourhassanMoghaddam, M., Maleki, M.J., Soozangar, N., Jeddi, F., Nouri, M., Zarghami, N., PilehvarSoltanahmadi, Y., 2018. Biomimetic synthesis of silver nanoparticles using Matricaria chamomilla extract and their potential anticancer activity against human lung cancer cells. Materials Science and Engineering: C, 92: 902-912.

Dehvari, M., Ghahghaei, A., 2018. The effect of green synthesis silver nanoparticles (AgNPs) from Pulicaria undulata on the amyloid formation in $\alpha$ lactalbumin and the chaperon action of $\alpha$ casein. International Journal of Biological Macromolecules, 108: 1128-1139.

Elshikh, M., Ahmed, S., Funston, S., Dunlop, P., McGaw, M., Marchant, R., Banat, I.M., 2016. Resazurin-based 96-well plate microdilution method for the determination of minimum inhibitory concentration of biosurfactants. Biotechnology Letters, 38(6): 1015-1019.

Eren, A., Baran, M.F., 2019. Green synthesis, characterization and antimicrobial activity of silver nanoparticles (AgNPs) from maize (Zea mays). Applied Ecology and Environmental Research, 17(2): 4097-4105.

Francis, S., Joseph, S., Koshy, E.P., Mathew, B., 2017. Green synthesis and characterization of gold and silver nanoparticles using Mussaenda glabrata leaf extract and their environmental applications to dye degradation. Environmental Science and Pollution Research, 24(21): 17347-17357.

Gopinath, K., Kumaraguru, S., Bhakyaraj, K., Mohan, S., Venkatesh, K. S., Esakkirajan, M., Kaleeswarran, P.R., Naiyf, S.A., Kadaikunnan, S., Govindarajan, M., Benelli, G., Arumugam, A., 2016. Green synthesis of silver, gold and silver/gold bimetallic nanoparticles using the Gloriosa superba leaf extract and their antibacterial and antibiofilm activities. Microbial Pathogenesis, 101: 1-11.

Gupta, S., Kumar, V., Joshi, K.B., 2017. Solvent mediated photo-induced morphological transformation of AgNPs-peptide hybrids in waterEtOH binary solvent mixture. Journal of Molecular Liquids, 236: 266-277.

Khan, Z.U.H., Khan, A., Chen, Y.M., Shah, N.S., Khan, A.U., Muhammad, N., Tahir, K., Shah, H.U., Khan, Z.U., Shakeel, M., Nadeem, M., Imran, M., Wan, P., 2018. Enhanced antimicrobial, anti-oxidant applications of green synthesized AgNPs-an acute chronic toxicity study of phenolic azo dyes \& study of materials surface using X-ray photoelectron spectroscopy. Journal of Photochemistry and Photobiology B: Biology, 180: 208-217.

Kim, S.W., Jung, J.H., Lamsal, K., Kim, Y.S., Min, J.S., Lee, Y.S., 2012. Antifungal effects of silver nanoparticles (AgNPs) against various plant pathogenic fungi. Mycobiology, 40(1): 53-58.

Kumar, B., Smita, K., Cumbal, L., Debut, A. 2017. Green synthesis of silver nanoparticles using Andean blackberry fruit extract. Saudi Journal of Biological Sciences, 24(1): 45-50.

Kung, J.C., Chen, Y.J., Chiang, Y.C., Lee, C.L., Yang- 
Wang, Y.T., Hung, C.C., Shih, C.J., 2018. Antibacterial activity of silver nanoparticle (AgNP) confined mesoporous structured bioactive powder against Enterococcus faecalis infecting root canal systems. Journal of Non-Crystalline Solids, 502(15): $62-70$.

Lakshman Kumar, D., Siva Sankar, S., Venkatesh, P., Hepcy Kalarani, D., 2016. Green synthesis of silver nanoparticles using aerial parts extract of Echinochloa colona and their characterization. European Journal of Pharmaceutical Medical Research, 3(4): 325-328.

Pallela, P.N.V.K., Ummey, S., Ruddaraju, L.K., Pammi, S.V.N., Yoon, S.G., 2018. Ultra Small, mono dispersed green synthesized silver nanoparticles using aqueous extract of Sida cordifolia plant and investigation of antibacterial activity. Microbial Pathogenesis, 124: 63-69.

Rajan, R., Chandran, K., Harper, S.L., Yun, S.I., Kalaichelvan, P.T., 2015. Plant extract synthesized silver nanoparticles: an ongoing source of novel biocompatible materials. Industrial Crops and Products, 70: 356-373.

Saravanakumar, K., Chelliah, R., Shanmugam, S., Varukattu, N.B., Oh, D.H., Kathiresan, K., Wang, M.H., 2018. Green synthesis and characterization of biologically active nanosilver from seed extract of Gardenia jasminoides Ellis. Journal of Photochemistry and Photobiology B: Biology, 185: 126-135.

Selvakumar, P., Sithara, R., Viveka, K., Sivashanmugam, P., 2018. Green synthesis of silver nanoparticles using leaf extract of Acalypha hispida and its application in blood compatibility. Journal of Photochemistry and Photobiology B: Biology, 182: 52-61.
Selvam, K., Sudhakar, C., Govarthanan, M., Thiyagarajan, P., Sengottaiyan, A., Senthilkumar, B., Selvankumar, T., 2017. Eco-friendly biosynthesis and characterization of silver nanoparticles using Tinospora cordifolia (Thunb.) Miers and evaluate its antibacterial, antioxidant potential. Journal of Radiation Research and Applied Sciences, 10(1): 6-12.

Singh, V., Shrivastava, A., Wahi, N., 2015. Biosynthesis of silver nanoparticles by plants crude extracts and their characterization using UV, XRD, TEM and EDX. African Journal of Biotechnology, 14(33): 2554-2567.

Song, J.Y., Kim, B.S., 2009. Rapid biological synthesis of silver nanoparticles using plant leaf extracts. Bioprocess and Biosystems Engineering, 32(1): 7984.

Stevanović, M.M., Škapin, S.D., Bračko, I., Milenković, M., Petković, J., Filipič, M., Uskoković, D.P., 2012. Poly (lactide-co-glycolide)/silver nanoparticles: Synthesis, characterization, antimicrobial activity, cytotoxicity assessment and ROS-inducing potential. Polymer, 53(14): 2818-2828.

Wang, M., Zhang, W., Zheng, X., Zhu, P., 2017. Antibacterial and catalytic activities of biosynthesized silver nanoparticles prepared by using an aqueous extract of green coffee bean as a reducing agent. RSC Advances, 7(20): 12144-12149.

Xu, H., Shi, X., Ma, H., Lv, Y., Zhang, L., Mao, Z., 2011. The preparation and antibacterial effects of dopa-cotton/AgNPs. Applied Surface Science, 257(15): 6799-6803.

Yang, G., Xie, J., Deng, Y., Bian, Y., Hong, F., 2012. Hydrothermal synthesis of bacterial cellulose/AgNPs composite: a "green" route for antibacterial application. Carbohydrate Polymers, 87(4): 2482-2487. 